\title{
Teachers Attitude Towards Functionality Geogebra software in Mathematics
}

\author{
Sinta Dameria Simanjuntak ${ }^{1}$, Tetty Natalia Sipayung ${ }^{2}$ \\ ${ }^{12}$ Lecturer, Universitas Katolik Santo Thomas, Jl. Setia Budi No.479F, Tanjung Sari, Kota Medan, Sumatera \\ Utara 20154, Indonesia
}

\begin{abstract}
Attitude is a tendency to take sides or reject an idea, a concept or a particular idea. Attitude is said positive if it has a tendency to side with something and vice versa, lecturer in Indonesia, in general, are still not using technology in learning activity because various factors affecting the bleak facilities were inadequate, the inability to integrate technology and tend to have a negative attitude in the use of technology. Geogebra is a software that could utilize in the process of learning mathematics. The purpose of this study to analyse how the attitudes of teachers towards the use of Geogebra software in teaching Mathematics.
\end{abstract}

Keyword: Teacher Activity, Attitude Teaching, Geogebra Software, Mathematics Teacher

\section{Introduction}

The progress of time together with the development of advanced science and technology, because it is in the process of education and learning should be developed teaching method with the use of technology as a teaching aid due to having an advantage in its use. Sudjana (2007) reveals there are seven benefits of the use of computers in learning, advantages are:

1. How new work with a computer will generate motivation to students in learning.

2. Color, music, graphics and animations can add a sense of realism and demand exercises, laboratory activities, simulations and else.

3. The rapid personal response in the activities of student learning will result in a high strengthening

4. The memory capability allows the appearance of past students who have recorded and used in planning the next steps in the future.

5. Patience, personal habits that can be programmed complements the atmosphere of a more positive attitude, particularly useful for students who are slow.

6. Ability power recorder allows individual instruction could execute, the commands are given to each so could be prepared for all students, in particular for students who are devoted, and their learning progress could be view

7. The range widened teacher supervision in line with the amount of information presented easily and arranged by teachers, and help monitor closer to the direct contact with the students.

There are several ways can do with the use of computers in the teaching process, for example as follows:

1. Tuition that students learn on their own from a program that is already on the computer with the established order in accordance learning

2. The computer simulation that can provide an overview of specific data

3. Data-crunching that computers used as an extensive research for collecting an amount of data.

This research describes the use of Geogebra software as a learning tool for students of mathematics and the resulting impact on the teaching process.

\section{Theories}

GeoGebra is a mathematics software that combines geometry, algebra, and calculus. GeoGebra developed by Markus Hohenwarter at the University of Salzburg for mathematics education in schools. GeoGebra is a dynamic geometry system. Through the construction of GeoGebra can be done by utilizing dots, vectors, segments, lines, conic sections and functions that can be changed dynamically, in Geogebra any equations and coordinates can be input directly. Thus, GeoGebra can connect variables with numbers, vectors with points find derivatives and integrals of functions and providing the commands as root and much more.

GeoGebra is a dynamic geometry system. This program can be used to construct points, vectors, lines, conic, and functions and change them dynamically, in addition to the benefits already mentioned, there are several advantages of the program GeoGebra compared to other geometry software. Among them are:

1. Tool in GeoGebra is simple, uncomplicated and not much so it will not make students' confusion

2. Each display on the geometry of the window represented in the algebra window in the form of the equation so as to facilitate the students if they want to explore the properties and the pattern of the thing 
3. Function or the coordinates of the point can be directly inserted in the input file and will appear in the geometry window. Thus from the file of entry function or the coordinates of points can be changed for exploration

4. geometry window images can be altered dynamic so that it can observe

5. The equations can be edited to generate a geometry that is expected to allow for exploration.

Attitudes can define as a person's tendency to accept or reject the concept, the idea of a collection or group of individuals. GeoGebra generated on a lot of ideas and concepts that aim to help the learning process of Mathematics. Thus, GeoGebra can be addressed by teachers in different ways with the possibility to accept or reject GeoGebra itself. Based on the observations of researchers in schools a place of research, the faculty still incorporate the technology into the learning process activities. The faculty still only use the whiteboard, markers and student handbook. Thus, the integration of technology in learning will be something new for the lecturer special software GeoGebra. Based on that idea, the researchers wanted to analyze the attitudes of teaching staff towards the use of technology in learning activities.

\section{Evaluation}

This type of research utilized descriptive study. The sample in this research is the permanent teachers in private primary schools Antonius V field consisting of 19 class teachers. Variables examined in this study is the attitude of teachers towards the use of software Geogebra in learning. The study involved non-test instrument that questionnaire. Because this study aimed to analyze the attitudes of teachers towards the use Geogebra in learning and then analyzed with the descriptive statistics analysis.

The questionnaire results of this research will be discussed item by item to sharpen the analytical results teacher attitudes towards the use of technology specifically GeoGebra in learning Mathematics. For the number one item questionnaire, $47 \%$ of teachers agree that introducing Flat (triangle, square, rectangle, parallelogram, rhombus, kite, trapezoidal and circle) will be easier on students. The rest as much as 53\% stated strongly agree. A total of 53\% of teachers agreed that identify the properties Flat (triangle, square, rectangle, parallelogram, rhombus, kite, trapezoidal and circle) will be easier on students. The rest $47 \%$ stated strongly agree. A total of $53 \%$ of teachers agreed that finding the area and perimeter Flat (triangle, square, rectangle, parallelogram, rhombus, kite, trapezoidal and circle) will be easier for students. The rest $47 \%$ of teachers stated strongly agree. $37 \%$ of teachers agreed that students would be more motivated to learn the spirit and flat wake, while $63 \%$ stated strongly agree. 58\% of teaching staff said that introduce/define and measure the angle becomes easier, while the remaining $42 \%$ stated strongly agree, $68 \%$ lecturers agree that students more easily to recognize/determine/measure the angle. The rest $32 \%$ stated strongly agree. 53\% of teaching staff agree that it is easier to introduce and identify the geometry (cube, block, pyramid, prism, and cone), while $47 \%$ of the excess stated strongly agree. 53\% of teaching staff agreed that more easily show a pure geometry (cube, block, pyramid, prism and cone). The rest $47 \%$ stated strongly agree. 53\% energy chaser agree that it is easier to explore volume geometry (cube, block, pyramid, prism, and cone). The rest $47 \%$ stated strongly agree. 53\% of teaching staff agreed that more easily explore the rectangular coordinate system and data processing. $47 \%$ stated strongly agree. $42 \%$ lecturers decided that mathematics using GeoGebra easier and more enjoyable.58\% of teacher strongly agree for item questionnaire containing statements "GeoGebra will make students the courage to express the idea that students became more confident".

Results showed that $6 \%$ of teaching staff disagreed, $47 \%$ agreed, and $47 \%$ stated strongly agree, for the 13 item questionnaire that reads "I feel overwhelmed using the tools in GeoGebra", 32\% stated strongly agree, $47 \%$ disagree, $16 \%$ agree, and the remaining $5 \%$ stated strongly agree, as many as $47 \%$ of teaching staff agreed that they are motivated to carry out the study of mathematics with GeoGebra software. The remaining 53\% stated strongly agree. $16 \%$ of teachers stated strongly disagree that they are lacking the spirit of conduct mathematical learning using computers because they do not understand computers, $16 \%$ agree, $47 \%$ agree, and the remaining $21 \%$ stated strongly agree. For item questionnaire that reads "By using the software GeoGebra, I can improve classroom management," $42 \%$ of the teaching force states and the remaining $58 \%$ stated strongly agree. As many as $16 \%$ of teachers stated strongly disagree that they are difficult to explain the material related to the geometry of the students as they require special tools, $37 \%$ disagreed, $31 \%$ agree, and the remaining $16 \%$ stated strongly agree. $37 \%$ of teaching staff decided that they wanted to try the exercises GeoGebra software application is more to learning, the remaining $63 \%$ stated strongly agree. To questionnaire item number 19 , which contains the statement that "learning by using GeoGebra waste of time," $16 \%$ of teaching staff stated strongly disagree, $11 \%$ agree, $47 \%$ agree and $26 \%$ stated strongly agree, as many as $42 \%$ of teachers decided that learning with the GeoGebra will add curiosity of students. The remaining 58\% stated strongly agree.

The tutor will observe the following item questionnaire and the research data shows that there are four faculty members $(21 \%)$ said they felt overwhelmed in using GeoGebra tool. A total of 13 faculty members or about $68 \%$ of teaching staff expressed less enthusiasm held computers for learning with less computer savvy. Furthermore, nine faculties (47\%) lecturer states find it hard to explain the material related to the geometry 
because it requires special tools. There are 14 faculty members, or about $74 \%$ of the teaching force was learning by using GeoGebra squander time. The rest $100 \%$ lecturers agreed about 16 remaining residual item questionnaire. Thus it can be said, that the majority of software is very helpful GeoGebra faculty task in implementing the learning. Alternatively, it can also be said, the majority of teaching staff have a response or a positive attitude in the integration of GeoGebra in learning Mathematics. The lowest overall score on the questionnaire is 0 , and the highest score was 80 . The median of that score is 40 . If viewed from a median score, can be said to be $100 \%$ of teaching staff have a positive attitude towards the use GeoGebra in learning because the faculty lowest score is 56 greater than 40 . The average score obtained attitude is 66 . When compared to the value that $58 \%$ of lecturers have scores below average and rest were $42 \%$ have a score above average.

\section{Conclusion}

Based on the analysis of data and research findings, the researchers came to the conclusion that $100 \%$ of teaching staff have a positive attitude towards the use GeoGebra in learning Mathematics. Only a few faculty members experienced problems in the use of computers, utilization and application of GeoGebra tool in learning, so to overcome this requires training and learning more.

\section{References}

[1]. Khairani, H. Makmun.2013. Psikologi Belajar. Yogyakarta: Aswaja Pressindo.

[2]. http://wiki.geogebra.org/en/Tutorial\%3AMain_Page

[3]. Mehanovic, Sanela. 2011. The Potential and Challenges of the Use of Dynamic Software in Upper Secondary Mathematics Students' and Teachers'Work with Integrals in Geogebra Based Environments. Sweden : Department of Mathematics Linkoping University.

[4]. Mehdiyev, Rafiq. 2009. Exploring students' learning experiences when using a Dynamic Geometry Software (DGS) tool in geometry class at asecondary school in Azerbaijan. Netherlands: Universitas van Amsterdam.

[5]. Seeley, Cathy L. 2006. Technology is a Tool,http://www.nctm.org/News-and-Calendar/Messages-from-thePresident/Archive/ Cathy-Seeley/Technology-Is-a-Tool/

[6]. Slavin, Robert E. 2008, Psikologi Pendidikan Teori dan Praktik, Jakarta : PT Indeks.

[7]. Sudjana, Nana dan Ahmad Rivai. 2007. Teknologi Pengajaran. Bandung: Sinar Baru Algesindo

[8]. Olsen, James. Top Ten Reason for Using Computers and Calculators to Help Student Learn Mathematic, http://faculty.wiu.edu/JROlsen/wiu/tea/top10tech.ppt 